Sozinov, A., Bakhchina, A., \& Alexandrov, Y. (2021). The way of learning preserved in the structure of individual experience shapes task-switching: Implications for neuroscience and education, International Journal of Cognitive Research in Science, Engineering and Education (IJCRSEE), 9(2), 291-299.

Review Article

\title{
The Way of Learning Preserved in The Structure of Individual Experience Shapes Task-Switching: Implications for Neuroscience and Education
}

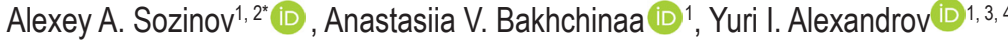 \\ ${ }^{1}$ Institute of Psychology RAS, Moscow, Russian Federation, e-mail: sozinovaa@ipran.ru \\ ${ }^{2}$ State Academic University for the Humanities, Moscow, Russian Federation, e-mail: bakhchinaav@ipran.ru \\ ${ }^{3}$ Moscow State University of Psychology \& Education, Moscow, Russian Federation, \\ ${ }^{4}$ HSE University, Moscow, Russian Federation, e-mail: yuraalexandrov@yandex.ru
}

\begin{abstract}
Task switching is a behavioral phenomenon that serves as a tool for assessment of individual cognitive abilities that becomes especially essential in our multitasking milieu. Factors of task-switching include cognitive load and cognitive effort, mostly derived from task difficulty, as well as age and practice. The analysis of brain activity on the level of single neurons shows that the activations that contribute to task performance and switching differ with respect to the protocol of learning the alternated tasks. We argue that task switching is affected by the history of learning and in turn it changes the structure of individual experience. On this basis we outline perspectives of task switching studies in the fundamental field of long-term memory and applied field of education and therapy.

Keywords: task switching, history of learning, single-neuron activity, memory reorganization, systems.
\end{abstract}

\section{Introduction}

The necessity to change behavior (e.g., to interrupt the current one and switch to another) is usually perceived as a burden, because getting back to where you formerly stopped requires effort that would not be made without the interruption. The analysis of the effort informs several fields of research that acquire more practical value along with the spread of digital communication technologies. First, task switching is a diagnostic tool that allows to assess individual status of behavioral control (cognitive flexibility) along with its relation to brain activity and potential treatment (e.g., Dajani and Uddin, 2015; Kozlovsky et al., 2012). Individual traits related to switching can also be assessed with self-report questionnaires (Umemoto and Holroyd, 2016).

Second, task switching is considered as a tool to study the components of putative cognitive processes via variation of task difficulty, age of participants, proficiency of task performance etc. (Arrington et al., 2003; Calcott and Berkman, 2015; Velichkovsky, B. B. and Ziberova, 2021; Wylie and Allport, 2000). The effort that is made for behavioral change is usually manifested in a decrease of speed and accuracy in trials that follow task switching compared to trials where the task is repeated, termed the switch costs. The correlates and determinants of the switch costs reveal the processes that underlie successful adaptation of behavior.

The present review is aimed at highlighting several consequences of the third aspect of the task switching phenomenology - that of switching as a separate task that has to be acquired by learning an aspect disclosed from the framework of cognitive plasticity (Mercado, 2008). We apply theoretical bases of systems psychophysiology (Alexandrov, 2015; Alexandrov et al., 2018; Shvyrkov, 1990) and the results of experimental studies to analysis of task switching as a form of memory and formulate potential implications that can be verified in future basic and applied research. This approach allows to describe changes in the systemic structure of behavior during the formation of a new action, to compare these structures between alternated actions, as well as to account for the influence of the learning history on this structure.

"Corresponding author: sozinovaa@ipran.ru 
Sozinov, A., Bakhchina, A., \& Alexandrov, Y. (2021). The way of learning preserved in the structure of individual experience shapes task-switching: Implications for neuroscience and education, International Journal of Cognitive Research in Science, Engineering and Education (IJCRSEE), 9(2), 291-299.

\section{Single-neuron activity and the structure of individual experience}

The analysis of single-neuron activity during task performance reveals task-related neurons and allows to assess the "sameness" of events for a given neuron. For example, recording of neuronal activity in human hippocampus (e.g., Quiroga et al., 2005) showed that some neurons increased firing upon presentation of images or sounds that point to the same object independent of the way of reference (different pictures of celebrities, their written or spoken names). Since these events are indistinguishable on the basis of activity of such neurons, the latter are considered to maintain the identity of an item in memory (Rey et al., 2020).

Importantly, increased firing of the same neuron accompanied viewing of Bahai Temple and Sydney Opera images in those participants who did not distinguish these two buildings, and was in different neurons in those who did (Quiroga et al., 2005). In other words, the sameness or difference derived from the task-related activity of the neurons reveals identity of subjective categories, or differentiation of subjects' interactions with the environment (see also Shvyrkov, 1990). Distinctions between subjective units have been also made on the basis of the analysis of single neuron activity (Alexandrov et al., 1997; Shvyrkov, 1990) recorded from rabbits' cingulate cortex (Alexandrov et al., 1990, 2001), motor cortex (Aleksandrov et al., 2005), and other structures, including hippocampus (Alexandrov et al., 2013). Consequently, although the concept cells are attributed to hippocampus, and not to the cortex (Rey et al., 2020), the analysis of such "identity" is possible for neurons in other structures. This analysis is based on the theory of functional systems (Anokhin, 1974) where function is defined as achievement of a result an adaptive organism-environment interaction - and on systems-evolutionary approach (Shvyrkov, 1990) that considers learning as formation of a new functional system via an evolution-like process of selection of neurons and their specialization in relation to a system (Shvyrkov, 1986; see also Alexandrov et al., 2017,2018 ). Within this framework, learning is creating a new function - that of achievement of a result through realization of the system - a new element of individual experience, whereas the behavior is subserved by realization of multiple systems formed at different stages of learning and development. The specialization of neurons, manifested in activation upon every instance of certain behavioral act, is what allows to reveal the elements of individual experience, analyze relations between these elements (Shvyrkov, 1990), describe the structure of individual experience that constitutes the subjective division of the world (Alexandrov, 2008). Since the behavior of every organism is aimed at its own results, this approach is universally suitable for humans and other animals.

A standard experimental setup in our single-neuron activity studies, aimed at description of structure of individual experience and principles of its formation, includes a square chamber with two feeders in adjacent corners and two pedals opposite to the feeders, where pressing of a pedal leads to receiving a portion of food in the feeder on the same side of the chamber (see Sozinov et al., 2021 for more details). A cycle of movements from pedal pressing to food uptake and back is divided into several behavioral acts on the basis of the stages of learning that preceded the final definitive behavior. When one pedal is effective, the other is always off, and the "effective side" of the chamber is changed every 7-15 effective cycles. Therefore, the final behavior of animals is switching the symmetric sides of the chamber signaled by absence of food after pressing and delivery of food on the now effective side. A specialized neuron is the one that has activation in every instance of a certain act (or acts). The cells that do not fit the specialization criteria are called unidentified (see also Alexandrov et al., 2018).

One of the key principles formulated and verified within the systems-evolutionary approach is that formation of new systems does not rewrite or delete previously formed ones (Alexandrov et al., 2018; Gorkin et al., 2018; Shvyrkov, 1990; Svarnik et al., 2020) - the new experience is added to, or "overlayed" on them. This is in correspondence with multiple evidence that the specializations of neurons are long-lasting, and apparently irreversible (Clopath et al., 2017; Gorkin and Shevchenko, 1991; McMahon et al., 2014; Thompson and Best, 1990). Therefore, of principal importance for the structure of individual experience is the history of learning, i.e. the timing and order of acquisition of behavioral acts. Consequently, the key point of neuronal activity analysis is the comparison of samples of neurons (their specializations, firing indices etc.) with respect to the history of learning, given that these samples were recorded during final behavior that was similar for the groups of animals.

Comparison of subsets of posterior cingulate cortex neurons specialized in relation to a system of the same behavioral act between groups of animals that acquired these behavioral acts in different order has shown that the relations between elements of individual experience portray the structure of the task and the order of learning (Gorkin and Shevchenko, 1996; Kuzina and Aleksandrov, 2020). Therefore, the structure of individual experience (in other terms, the way interactions with the environment are categorized, differentiated, or represented by the individual) is affected by the history of learning (see also 
Sozinov, A., Bakhchina, A., \& Alexandrov, Y. (2021). The way of learning preserved in the structure of individual experience shapes task-switching: Implications for neuroscience and education, International Journal of Cognitive Research in Science, Engineering and Education (IJCRSEE), 9(2), 291-299.

Alexandrov et al., 2018).

In a different study (Sozinov et al., 2008) the animals consecutively acquired two alternative ways to get food - ring pulling and pedal pressing. One group acquired the pedal-pressing task less than 3 hours after ring-pulling had been acquired on the same side of the chamber. These animals alternated these two forms of appetitive behavior on the same side for three more days before training on the other side in the same order. This schedule resembles massed and mixed learning (e.g., Rohrer and Taylor, 2007). The other group performed the ring-pulling for three days after its acquisition, acquired ring pulling on the other side of the chamber, and only then received the pedal-pressing task. This schedule resembles blocked and spaced learning (Rohrer and Taylor, 2007). Again, the final definitive behavior of animals from different groups were outwardly indistinguishable.

The relative number of specialized neurons was similar in the two groups. However, we then calculated the numbers of specialized cells similarly involved in both ways of behavior (specialized in relation to the same acts of the ring-pulling and pedal-pressing behavior, for example, approaching the ring and approaching the pedal on the same side of the chamber) and the numbers of the neurons that "differentiated" the rings and the pedals (involved in either ring-pulling, or pedal-pressing). The latter number was significantly smaller in the first group than in the second, implying that the two ways of behavior were represented more "independently" in animals of the first group (see also Kazymaev et al., 2012)

Finally, using the single-unit activity recording in rabbits' anterior and posterior areas of cingulate cortex during alternation of operant appetitive behavior on the two sides of the chamber, we have shown that the dynamics of neuronal activity after switching differs with respect to the degree of the neuron's involvement in task execution (Sozinov et al., 2021). The spike frequency of specialized anterior cingulate cortex cells increased after switching in their specific acts. Meanwhile, the frequency in other acts and in unidentified cells decreased after switching. No significant changes have been revealed in the posterior cingulate cortex neurons, although there were considerable changes similar to the previous results from our lab (Alexandrov et al., 1999). These results show that the specialized neurons (although their activations occur in every instance of a behavioral act) increase their degree of involvement after switching, thus reorganizing the subserving of task performance (by selection of neurons, see Johnston et al., 2007; Sozinov et al., 2021). This underscores the importance of further demonstrations of neuronal activity changes induced by switching during learning the tasks.

To summarize this section, we propose the following conclusions:

1. The specialization of neurons reveals subjectively similar and divergent interactions with the environment and affords comparison of samples of neurons with respect to the history of learning;

2. Switching the tasks during learning impacts the structure of individual experience that underlies task performance;

3. Switching the tasks acquired earlier might also change the relations between their underlying systemic structures.

These considerations point to the importance of the view on task switching as a stage of learning. In a similar way as the neuronal activity in anterior cingulate areas is related to performing the tasks (Johnston et al., 2007; Sozinov et al., 2021; Weible et al., 2009), switch-related activity (e.g., Ma et al., 2019) is task-related: performance of switching is also a task, and its solution is associated with the deployment of learning. In the terms of the task space (see Hirsch et al., 2018; Weible et al., 2009), this would imply that switching is not only a dynamic function within the space of alternated tasks that can be used as ready-made blocks. Switching is also one of the tasks that has to be learned. It changes the structure of individual experience and can therefore be a powerful tool in solving applied problems.

\section{Task switching is construction of individual experience}

According to the theoretical view explicated above, we consider switching as a misleading metaphor, likening the processes that underlie task switching to operation of electric circuits, and potentially implying that the switched circuits and the switch itself are separate details that do not change during switching. Not only our approach, but also both the conditioned reflex (e.g., Timofeeva et al., 1997) and cognitive (e.g., Rubinstein et al., 2001) frameworks reveal that formation of task switching is a hetero-geneous process that shares the properties of any other learning.

Cognitive approach presumes that task switching is subserved at multiple levels (associative and cognitive - Chiu and Egner, 2017; emotional and cognitive - Vermeylen et al., 2019), including higher level representation of task pairs in dual tasks (Hirsch et al., 2018). In the latter study the switch cost has 
Sozinov, A., Bakhchina, A., \& Alexandrov, Y. (2021). The way of learning preserved in the structure of individual experience shapes task-switching: Implications for neuroscience and education, International Journal of Cognitive Research in Science, Engineering and Education (IJCRSEE), 9(2), 291-299.

been shown for switching between pairs of tasks with the corresponding signals presented with different "stimulus onset asynchrony" (see Hirsch et al., 2018 for more details). In other words, besides describing alternation of two tasks by means of top-down control processes, this approach also describes a global goal, making of one task - that of switching (e.g., Koch et al., 2018). This displays the formation of task switching as emergence of a new representation, or a new long-term memory unit. In our view, this line on the theoretical picture of task switching designates wide perspective.

According to the definition that we elaborate, learning is formation of a new element of individual experience and corresponding reorganization (reconsolidation) of earlier formed elements that contribute to the new behavior (Alexandrov et al., 2001). Task switching seems to manifest features of both processes. Near transfer of switching and absence of far transfer shown in students (Zhao et al., 2020; see also Jones and Moss, 2019) illustrates that the processes that underlie switching include formation of a memory unit or, in our terms, a unit of individual experience. A more heterogeneous results on training and transfer of "cognitive flexibility" in adolescence (Buttelmann and Karbach, 2017) also reveal the importace of analizing the history of experience formation, since individual units of experience grow into multilevel organization of task switching phenomena (see previous paragraph and Shvyrkov, 1990).

The seminal work by Wylie and Allport (2000) has shown that the interference effect taken as a measure of task-set reconfiguration is spread far beyond a single switch trial, and that modification of memory occurs on every trial. Gradual decrease of switching costs during extensive practice (Strobach et al., 2012; Zhao et al., 2020) and the dependence of switch costs on task similarity (Arrington et al., 2003) also show that switching leads to reorganization or individual experience.

The view of task switching as a result of executive control processes over associative mechanisms implies that learning to switch between tasks, manifested in reduction of costs as a result of practice, is based on "cognitive plasticity", i.e. connecting the task performance mechanisms to a higher-level "computational power" (e.g., Mercado, 2008). The latter is assumed to be provided by the activity in prefrontal and cingulate cortices (Bryden et al., 2019; Kuwabara et al., 2014; Ma et al., 2019; Zhang and Williams, 2015). However, no brain area (or several areas) seems to show activity related to task switching per se without relevance to the task (Calcott and Berkman, 2015; Dreher et al., 2002; but see De Baene et al., 2015). Meanwhile, aspects of functioning ascribed to anterior cingulate cortex, i.e. recent (Gabriel, 1993) and remote (Frankland et al., 2004; Weible, 2013) memory (see also Tonegawa et al., 2018), task switching and dual task performance (Dreher and Grafman, 2003), novelty (Barcelo et al., 2006), conflict or error detection (see Bryden et al., 2019; Hyman et al., 2017) and other dynamic aspects of behavior, share the same feature - a necessity of memory reorganization. This highlights the importance of learning process in manifestation of the so-called cognitive functioning.

The view of task switching as a result of learning that includes reorganization of individual experience leads to a set of research perspectives. First, if task switching is provided by formation of a new memory, it would be of theoretical importance to study whether it undergoes consolidation, incubation, reconsolidation, and/or any other process inherent to memories (e.g., Dudai et al., 2015) analogous to studies of extinction as a new memory (see Davis et al., 2017).

Second, if task switching leads to changes of prior experience akin to memory reconsolidation, switching can inspire applied studies in education and therapy. We elaborate the former perspective in a separate section, whereas the parallels for the latter can be found in a review by Drexler and Wolf (2018).

Third, a much nearer consequence that can be inferred from the previous section is that the indices of switching depend on history of learning the alternated tasks. This prediction is discussed in the following section.

In brief, this section envelops that:

1. If learning to switch between tasks is formation of a new memory unit, then it not only leads to reorganization of memory, but also may be accompanied by consolidation and reconsolidation phenomena;

2. The view of task switching as a result of learning leads to research perspectives discussed in the following sections.

\section{Task switching and the history of learning}

The explanation of task switching by inhibition and inertia is mainly targeted via analysis of switch costs and manipulation of task complexity. For example, univalent and bivalent tasks are employed to reveal the effects of previous and current task on switch costs (Lien et al., 2006; Wylie and Allport, 2000). Variation of complexity also allows for assessment of age differences (see Wasylyshyn et al., 2011) and switch cost asymmetry (Yeung and Monsell, 2003). Besides complexity, the switch costs have also been 
Sozinov, A., Bakhchina, A., \& Alexandrov, Y. (2021). The way of learning preserved in the structure of individual experience shapes task-switching: Implications for neuroscience and education, International Journal of Cognitive Research in Science, Engineering and Education (IJCRSEE), 9(2), 291-299.

shown to be affected by the amount of practice (Strobach et al., 2012) and age (Wasylyshyn et al., 2011). Our theoretical considerations on the history of learning and results of single neuron activity recordings introduced above allow to propose that the schedule of learning may also affect task switching. Functions develop as achievement of adaptive results (Anokhin, 1974). What is called "cognitive functions", in our view, are also not static abilities or types of computation, but characteristics of the structure of individual experience formed as a result of learning (see also Alexandrov and Sams, 2005). Therefore, the formation of task switching, like any learning, is accompanied by reorganization of individual experience derived from the demands of the task (Alexandrov et al., 2018), i.e. forming a structure that unites elements of previous experience into one behavior.

Since the neurons specialized in relation to systems of new behavioral acts change their activity after task switching (Sozinov et al., 2021), and the set of these neurons differs with respect to learning protocol (Sozinov et al., 2008), it is possible that the measures of switching are affected by the history of learning. In accordance with this proposition, switching depends on task familiarity (e.g., Yeung and Monsell, 2003) and differs individually (e.g., Umemoto and Holroyd, 2016). The cross-language activation assessed via using cross-language homographs was shown to be sensitive to language experience (the first or the second language; Gullifer and Titone, 2019).

The rate of switching is associated with the order of tasks during learning. In our studies of neuronal activity after switching, the duration of transition of animals to the first-acquired side of the chamber was lower than to the second (Sozinov et al., 2021). This difference was significant during the first week of practice and disappeared afterwards. When the duration of transition was compared between the protocols of learning to acquire food with ring pulling and pedal pressing (Sozinov et al., 2008), switching to the first task appeared to be the longest after mixed (and massed) learning in comparison to the blocked learning and transitions to all other tasks.

Overall, this section illustrates that the indices of switching are affected by the learning history, which is in correspondence to the view of switching as reorganization of prior experience.

\section{Task switching and applied research in education}

One of the tools of education that involves the aspect of switching is arrangement of materials during teaching and practice. The massed/spaced (or distributed) and blocked/mixed schedules differ with respect to subsequent test performance, but there is no universal rule of efficacy (see Rohrer and Taylor, 2007; Son and Simon, 2012). The brain activity is known to be influenced by the teaching method, even when the behavioral measures do not reveal any effect (Brault Foisy et al., 2020). As we elaborate in the previous section, switching between the tasks is also part of the learning history. In the already mentioned articles by Gorkin and Shevchenko (1996) and by Sozinov et al. (2021) the order of acquired behavioral acts differed with respect to switching (changing the effective sides of the chamber) during learning, and all samples of neurons consisted of different sets of specializations. If the task switching shapes the structure of individual experience, it can serve not only an obstacle, but also as an instrument of educational practice.

According to our results on neuronal specializations described above (Sozinov et al., 2008), switching the tasks during learning was accompanied by greater divergence between them. One of the possible ways in which task switching may help learning is the contrast between alternated tasks that satisfies necessity of variation (Marton, 2006). Therefore, switching might be beneficial in learning to differentiate. This means that even in the absence of obvious differences of performance measures, the history of learning influences the structure of individual experience. Therefore, it potentially influences interference and/or transfer of the acquired knowledge during further learning. In this respect, the effect of switching is important issue for further research in neuroscience and applied studies in education.

An important attribute of modern communication is multitasking, which involves (Koch et al., 2018) or consists in (Hassed, 2016) task switching and inevitably infiltrates education (Srna, Schrift and Zauberman, 2018). The main predictor of success in multitasking is individual characteristics of working memory, not the age of participants or the amount of practice - members of the "digital generation" equally reduce their speed and accuracy when they have to use additional communication tools or digital technologies as the older participants (Carrier et al., 2015; Dindar and Akbulut, 2016). Also multitasking does not reveal an unambiguous effect on learning: it can decrease, increase, or have no effect on retention and topic interest (Carrier et al., 2015; Dindar and Akbulut, 2016). Our comparison of academic performance and switch costs between groups of schoolchildren who acquired two concepts with or without switching showed remote benefit of learning with switching accompanied by greater cognitive 
Sozinov, A., Bakhchina, A., \& Alexandrov, Y. (2021). The way of learning preserved in the structure of individual experience shapes task-switching: Implications for neuroscience and education, International Journal of Cognitive Research in Science, Engineering and Education (IJCRSEE), 9(2), 291-299.

effort (to be published after complete data analysis). Therefore, of importance is the "management" of multitasking that would increase the effectiveness of learning using segmentation of individual learning episodes, grouping of tasks by importance, and other tools of reorganization of experience (Stavtseva, 2014), and would possibly mediate the developing creative abilities (see Markina and Vladimirov, 2019; Zdanevych et al., 2020).

In this section we proposed the theoretical bases for and examples of using task switching in educational practice. If switching between tasks leads to changes in the structure of experience, switching itself can be a tool that allows for segmentation or integration of corresponding memories. Further research in neuroscience and education is needed to make use of this potential resource. If task switching restructured the links within acquired knowledge in a controllable way, the use of switching in education and therapy would be worth the cognitive effort.

\section{Conclusions}

The analysis of neuronal specializations in relation to systems of newly learned behavioral acts reveals subjective division (or "categories") of an organism-environment interaction. Subjects that performed similar over-learned behavior had specialization patterns that differed in accordance with their preceding learning protocols. The differentiation between the tasks on the neuronal level is greater in the group of animals that acquired both tasks in a quick succession (i.e. had interleaved, or massed, learning with risk of interference) compared to the group that acquired two versions of each task with extended practice (i.e. had spaced learning with greater transfer effect). These results and the behavioral indices of task performance show that the structure of experience derived from the history of learning may be stable and keeps influencing the performance after overlearning.

The activity of neurons in anterior and posterior cingulate cortex that changes in connection to task switching is the task-specific firing of the specialized cells. In other words, switching is substantially subserved by neurons involved in task execution. Correspondingly, we show that the behavioral indices of task switching are linked to the history of learning and explain it by irreversible specialization of neurons that largely subserve the switch.

These conclusions can be further developed in studies of brain activity dynamics, but we also consider them to serve a strong basis for applied research in educational settings. Since task switching is an important index of cognitive abilities and an inevitable necessity in social communication, it is of in-terest to compare task switching between declarative tasks in schoolchildren with different learning conditions (e.g., motivation, learning protocol etc.) to see if task switching can be used as a tool for assessing and changing of the acquired knowledge structure.

\section{Acknowledgements}

The study of individual experience structure based on the recording of neuronal activity had been supported by the Russian Science Foundation (grant \#18-78-10114). The analysis and application of data on switching had been supported by the Foundation for New Forms of Development of Education (FNFRO), contract \#RUOM1019 with the Institute of Psychology RAS.

\section{Conflict of interests}

The authors declare no conflict of interest.

\section{References}

Aleksandrov, Y. I., Grinchenko, Y. V., Shevchenko, D. G., Mats, V. N., Laukka, S., \& Averkin, R. G. (2005). Neuron activity in the anterolateral motor cortex in operant food-acquiring and alcohol-acquiring behavior. Neuroscience and Behavioral Physiology, 35(5), 501-509. https://doi.org/10.1007/s11055-005-0085-2

Alexandrov, Y. I. (2008). How we fragment the world: the view from inside versus the view from outside. Social Science Information, 47(3), 419-457. https://doi.org/10.1177/0539018408092580

Alexandrov, Y. I. (2015). Systemic psychophysiology. In C. Forsythe et al. (Eds.), Russian Cognitive Neuroscience: Historical and Cultural Context (pp. 65-100). CreateSpace Independent Publishing.

Alexandrov, Y. I., Grechenko, T. N., Gavrilov, V. V., Gorkin, A. G., Shevchenko, D. G., Grinchenko, Y. V., Aleksandrov, I. O., Maksimova, N. E., Bezdenezhnych, B. N., \& Bodunov, M. V. (1997). Formation and realization of individual experience. Neuroscience and Behavioral Physiology, 27(4), 441-454. https://doi.org/10.1007/BF02462946

Alexandrov, Y. I., Grinchenko, Y. V., Shevchenko, D. G., Averkin, R. G., Matz, V. N., Laukka, S., \& Sams, M. (2013). The Effect

www.ijcrsee.com 
Sozinov, A., Bakhchina, A., \& Alexandrov, Y. (2021). The way of learning preserved in the structure of individual experience shapes task-switching: Implications for neuroscience and education, International Journal of Cognitive Research in Science, Engineering and Education (IJCRSEE), 9(2), 291-299.

of Ethanol on the Neuronal Subserving of Behavior in the Hippocampus. Journal of Behavioral and Brain Science, 03(01), 107-130. https://doi.org/10.4236/jbbs.2013.31011

Alexandrov, Y. I., Grinchenko, Y. V, Laukka, S. J., Järvilehto, T., Matz, V. N., \& Svetlajev, I. A. (1990). Acute effect of ethanol on the pattern of behavioural specialization of neurons in the limbic cortex of the freely moving rabbit. Acta Physiologica Scandinavica, 140(2), 257-268. https://doi.org/10.1111/j.1748-1716.1990.tb08997.x

Alexandrov, Y. I., Grinchenko, Y. V., Shevchenko, D. G., Averkin, R. G., Matz, V. N., Laukka, S., \& Korpusova, A. V. (2001). A subset of cingulate cortical neurones is specifically activated during alcohol-acquisition behaviour. Acta Physiologica Scandinavica, 171(1), 87-97. https://doi.org/10.1046/j.1365-201X.2001.00787.x

Alexandrov, Y. I., Krylov, A. K., \& Arutyunova, K. R. (2017). Activity during learning and the nonlinear differentiation of experience. Nonlinear Dynamics, Psychology, and Life Sciences, 21(4), 391-405. Retrieved from https://lib.ipran.ru/upload/papers/ paper_31056164.pdf

Alexandrov, Y. I., \& Sams, M. E. (2005). Emotion and consciousness: Ends of a continuum. Cognitive Brain Research, 25(2), 387-405. https://doi.org/10.1016/j.cogbrainres.2005.08.006

Alexandrov, Y. I., Shevchenko, D. G., Gorkin, A. G., \& Grinchenko, Y. V. (1999). Dinamics of systems organization of behavior during consecutive trials [Dinamika sistemnoj organizacii povedenija v ego posledovatel'nyh realizacijah]. Psikhologicheskii Zhurnal, 20(2), 82-89.

Alexandrov, Y. I., Sozinov, A. A., Svarnik, O. E., Gorkin, A. G., Kuzina, E. A., \& Gavrilov, V. V. (2018). Neuronal bases of systemic organization of behavior. In Advances in Neurobiology (Vol. 21, pp. 1-33). Springer New York LLC. https:// doi.org/10.1007/978-3-319-94593-4_1

Anokhin, P. K. (1974). Biology and Neurophysiology of the Conditioned Reflex and Its Role in Adaptive Behavior. Pergamon Press.

Arrington, C. M., Altmann, E. M., \& Carr, T. H. (2003). Tasks of a feather flock together: Similarity effects in task switching. Memory and Cognition, 31(5), 781-789. https://doi.org/10.3758/BF03196116

Barcelo, F., Escera, C., Corral, M. J., \& Periáñez, J. A. (2006). Task switching and novelty processing activate a common neural network for cognitive control. Journal of Cognitive Neuroscience, 18(10), 1734-1748. https://doi.org/10.1162/ jocn.2006.18.10.1734

Brault Foisy, L. M., Matejko, A. A., Ansari, D., \& Masson, S. (2020). Teachers as orchestrators of neuronal plasticity: Effects of teaching practices on the brain. Mind, Brain, and Education, 14(4), 415-428. https://doi.org/10.1111/mbe.12257

Bryden, D. W., Brockett, A. T., Blume, E., Heatley, K., Zhao, A., \& Roesch, M. R. (2019). Single neurons in anterior cingulate cortex signal the need to change action during performance of a stop-change task that induces response competition. Cerebral Cortex, 29(3), 1020-1031. https://doi.org/10.1093/cercor/bhy008

Buttelmann, F., \& Karbach, J. (2017). Development and plasticity of cognitive flexibility in early and middle childhood. Frontiers in psychology, 8, 1040. https://doi.org/10.3389/fpsyg.2017.01040

Calcott, R. D., \& Berkman, E. T. (2015). Neural Correlates of Attentional Flexibility during Approach and Avoidance Motivation. PLOS ONE, 10(5), e0127203. https://doi.org/10.1371/journal.pone.0127203

Carrier, L. M., Rosen, L. D., Cheever, N. A., \& Lim, A. F. (2015). Causes, effects, and practicalities of everyday multitasking. Developmental Review, 35, 64-78. https://doi.org/10.1016/j.dr.2014.12.005

Chiu, Y. C., \& Egner, T. (2017). Cueing cognitive flexibility: Item-specific learning of switch readiness. Journal of Experimental Psychology: Human Perception and Performance, 43(12), 1950-1960. https://doi.org/10.1037/xhp0000420

Clopath, C., Bonhoeffer, T., Hübener, M., \& Rose, T. (2017). Variance and invariance of neuronal long-term representations. Philosophical Transactions of the Royal Society B: Biological Sciences, 372(1715), 20160161. https://doi.org/10.1098/ rstb.2016.0161

Dajani, D. R., \& Uddin, L. Q. (2015). Demystifying cognitive flexibility: Implications for clinical and developmental neuroscience. Trends in Neurosciences, 38(9), 571-578. https://doi.org/10.1016/j.tins.2015.07.003

Davis, P., Zaki, Y., Maguire, J., \& Reijmers, L. G. (2017). Cellular and oscillatory substrates of fear extinction learning. Nature Neuroscience, 20(11), 1624-1633. https://doi.org/10.1038/nn.4651

De Baene, W., Duyck, W., Brass, M., \& Carreiras, M. (2015). Brain circuit for cognitive control is shared by task and language switching. Journal of Cognitive Neuroscience, 27(9), 1752-1765. https://doi.org/10.1162/jocn_a_00817

Dindar, M., \& Akbulut, Y. (2016). Effects of multitasking on retention and topic interest. Learning and Instruction, 41, 94-105. https://doi.org/10.1016/j.learninstruc.2015.10.005

Dreher, J. C., \& Grafman, J. (2003). Dissociating the roles of the rostral anterior cingulate and the lateral prefrontal cortices in performing two tasks simultaneously or successively. Cerebral Cortex, 13(4), 329-339. https://doi.org/10.1093/ cercor/13.4.329

Dreher, J. C., Koechlin, E., Ali, S. O., \& Grafman, J. (2002). The roles of timing and task order during task switching. Neurolmage, 17(1), 95-109. https://doi.org/10.1006/nimg.2002.1169

Drexler, S. M., \& Wolf, O. T. (2018). Behavioral disruption of memory reconsolidation: From bench to bedside and back again. Behavioral Neuroscience, 132(1), 13-22. https://doi.org/10.1037/bne0000231

Dudai, Y., Karni, A., \& Born, J. (2015). The Consolidation and Transformation of Memory. Neuron 88(1), 20-32. Cell Press. https://doi.org/10.1016/j.neuron.2015.09.004

Frankland, P. W., Bontempi, B., Talton, L. E., Kaczmarek, L., \& Silva, A. J. (2004). The Involvement of the Anterior Cingulate Cortex in Remote Contextual Fear Memory. Science, 304(5672), 881-883. https://doi.org/10.1126/science.1094804

Gabriel, M. (1993). Discriminative Avoidance Learning: A Model System. In Neurobiology of Cingulate Cortex and Limbic Thalamus (pp. 478-523). Birkhäuser Boston. https://doi.org/10.1007/978-1-4899-6704-6_18

Gorkin, A. G., Kuzina, E. A., Ivlieva, N. P., Solov'eva, O. A., \& Aleksandrov, Y. I. (2018). Activity Patterns in Neurons in the Retrosplenial Area of the Cortex in Operant Food-Procuring Behavior in Rats of Different Ages. Neuroscience and Behavioral Physiology, 48(8), 1014-1018. https://doi.org/10.1007/s11055-018-0663-8

Gorkin, A. G., \& Shevchenko, D. G. (1991). Stability of the behavioral specialization of neurons. Neuroscience and Behavioral Physiology, 21(3), 222-229. https://doi.org/10.1007/BF01191659

Gorkin, A. G., \& Shevchenko, D. G. (1996). Distinctions in the neuronal activity of the rabbit limbic cortex under different training strategies. Neuroscience and Behavioral Physiology, 26(2), 103-112. https://doi.org/10.1007/BF02359413 
Sozinov, A., Bakhchina, A., \& Alexandrov, Y. (2021). The way of learning preserved in the structure of individual experience shapes task-switching: Implications for neuroscience and education, International Journal of Cognitive Research in Science, Engineering and Education (IJCRSEE), 9(2), 291-299.

Gullifer, J. W., \& Titone, D. (2019). The Impact of a Momentary Language Switch on Bilingual Reading: Intense at the Switch but Merciful Downstream for L2 but Not L1 Readers. Journal of Experimental Psychology: Learning Memory and Cognition, 45(11), 2036-2050. https://doi.org/10.1037/xIm0000695

Hassed, C. (2016). Mindful learning: Why attention matters in education. International Journal of School and Educational Psychology, 4(1), 52-60. https://doi.org/10.1080/21683603.2016.1130564

Hirsch, P., Nolden, S., Philipp, A. M., \& Koch, I. (2018). Hierarchical task organization in dual tasks: evidence for higher level task representations. Psychological Research, 82(4), 759-770. https://doi.org/10.1007/s00426-017-0851-0

Hyman, J. M., Holroyd, C. B., \& Seamans, J. K. (2017). A Novel Neural Prediction Error Found in Anterior Cingulate Cortex Ensembles. Neuron, 95(2), 447-456.e3. https://doi.org/10.1016/j.neuron.2017.06.021

Johnston, K., Levin, H. M., Koval, M. J., \& Everling, S. (2007). Top-Down Control-Signal Dynamics in Anterior Cingulate and Prefrontal Cortex Neurons following Task Switching. Neuron, 53(3), 453-462. https://doi.org/10.1016/j. neuron.2006.12.023

Jones, W. E., \& Moss, J. (2019). Assessing the transfer of interruption resumption skill to novel tasks. Journal of Experimental Psychology: Applied, 25(2), 230-244. https://doi.org/10.1037/xap0000193

Kazymaev, S. A., Sozinov, A. A., Grinchenko, Y. V., \& Alexandrov, Y. I. (2012). The reorganization of individual experience assessed via indices of brain activity dynamics. In V. A. Barabanschikov (Ed.), Experimental method in the structure of psychological knowledge (pp. 777-781). Institut psihologii RAN.

Koch, I., Poljac, E., Müller, H., \& Kiesel, A. (2018). Cognitive structure, flexibility, and plasticity in human multitasking-an integrative review of dual-task and task-switching research. Psychological Bulletin, 144(6), 557-583. https://doi. org/10.1037/bul0000144

Kozlovsky, S. A., Velichkovsky, B. B., Vartanov, A. V., Nikonova, E. Y., \& Velichkovsky, B. M. (2012). The role of the domains of the anterior cingulate cortex in the functioning of human memory. Experimental Psychology (Russia), 5(1), 12-22.

Kuwabara, M., Mansouri, F. A., Buckley, M. J., \& Tanaka, K. (2014). Cognitive control functions of anterior cingulate cortex in macaque monkeys performing a wisconsin card sorting test analog. Journal of Neuroscience, 34(22), 7531-7547. https://doi.org/10.1523/JNEUROSCI.3405-13.2014

Kuzina, E. A., \& Aleksandrov, Y. I. (2020). Characteristics of the Neuronal Support for Operative Behavior Formed by Monoand Multistep Methods. Neuroscience and Behavioral Physiology, 50(6), 710-722. https://doi.org/10.1007/s11055020-00959-2

Lien, M. C., Ruthruff, E., \& Kuhns, D. (2006). On the difficulty of task switching: Assessing the role of task-set inhibition. Psychonomic Bulletin and Review, 13(3), 530-535. https://doi.org/10.3758/BF03193881

Ma, L., Chan, J. L., Johnston, K., Lomber, S. G., \& Everling, S. (2019). Macaque anterior cingulate cortex deactivation impairs performance and alters lateral prefrontal oscillatory activities in a rule-switching task. PLoS Biology, 17(7), e3000045. https://doi.org/10.1371/journal.pbio.3000045

Markina, P. N., \& Vladimirov, I. Y. (2019). Executive function role on a stage of impasse in insight problem solving. Psychology. Journal of the Higher School of Economics, 16(3), 562-570. https://doi.org/10.17323/1813-8918-2019-3-562-570

Marton, F. (2006). Sameness and difference in transfer. Journal of the Learning Sciences, 15(4), 499-535. https://doi. org/10.1207/s15327809jls1504_3

McMahon, D. B. T., Jones, A. P., Bondar, I. V., \& Leopold, D. A. (2014). Face-selective neurons maintain consistent visual responses across months. Proceedings of the National Academy of Sciences of the United States of America, 111(22), 8251-8256. https://doi.org/10.1073/pnas.1318331111

Mercado, E. (2008). Neural and Cognitive Plasticity: From Maps to Minds. Psychological Bulletin, 134(1), 109-137. https://doi. org/10.1037/0033-2909.134.1.109

Quiroga, R. Q., Reddy, L., Kreiman, G., Koch, C., \& Fried, I. (2005). Invariant visual representation by single neurons in the human brain. Nature, 435(7045), 1102-1107. https://doi.org/10.1038/nature03687

Rey, H. G., Gori, B., Chaure, F. J., Collavini, S., Blenkmann, A. O., Seoane, P., Seoane, E., Kochen, S., \& Quian Quiroga, R. (2020). Single Neuron Coding of Identity in the Human Hippocampal Formation. Current Biology, 30(6), 1152-1159.e3. https://doi.org/10.1016/j.cub.2020.01.035

Rohrer, D., \& Taylor, K. (2007). The shuffling of mathematics problems improves learning. Instructional Science, 35(6), 481498. https://doi.org/10.1007/s11251-007-9015-8

Rubinstein, J. S., Meyer, D. E., \& Evans, J. E. (2001). Executive Control of Cognitive Processes in Task Switching. Journal of Experimental Psychology: Human Perception and Performance, 27(4), 763-797. https://doi.org/10.1037/00961523.27.4.763

Shvyrkov, V. B. (1986). Behavioral specialization of neurons and the system-selection hypothesis of learning. In F. Klix \& H. Hagendorf (Eds.), Human memory and cognitive capabilities (pp. 599-611). North-Holland: Elsevier.

Shvyrkov, V. B. (1990). Neurophysiological Study of Animals' Subjective Experience. In Machinery of the Mind (pp. 337-350). Birkhäuser Boston. https://doi.org/10.1007/978-1-4757-1083-0_17

Son, L. K., \& Simon, D. A. (2012). Distributed Learning: Data, Metacognition, and Educational Implications. In Educational Psychology Review (Vol. 24, Issue 3, pp. 379-399). Springer. https://doi.org/10.1007/s10648-012-9206-y

Sozinov, A. A., Averkin, R. G., Grinchenko, Y. V., \& Alexandrov, Y. I. (2008). Involvement of previous memory in learning and the transfer effect. International Journal of Psychophysiology, 69(3), 258. https://doi.org/10.1016/j.ijpsycho.2008.05.179

Sozinov, A. A., Grinchenko, Y. V., Bakhchina, A. V., Zubtsova, M., \& Alexandrov, Y. I. (2021). Subserving of task switching in rabbits' cingulate cortex neurons. In Boris M. Velichkovsky, P. M. Balaban, \& V. L. Ushakov (Eds.), Advances in Intelligent Systems and Computing (V.1358, pp. 439-451). Springer. https://doi.org/10.1007/978-3-030-71637-0_50

Srna, S., Schrift, R. Y., \& Zauberman, G. (2018). The Illusion of Multitasking and Its Positive Effect on Performance. Psychological Science, 29(12), 1942-1955. https://doi.org/10.1177/0956797618801013

Stavtseva, I. V. (2014). The principle of multitasking management in students' learning to read. In S. D. Vaulin (Ed.), The science in SUSU: proceedings of the 66-th conference (pp. 1317-1321). Izdatelski tsentr YuUGRU.

Strobach, T., Liepelt, R., Schubert, T., \& Kiesel, A. (2012). Task switching: Effects of practice on switch and mixing costs. Psychological Research, 76(1), 74-83. https://doi.org/10.1007/s00426-011-0323-x

Svarnik, O. E., Bulava, A. I., Gladilin, D. L., Nazhestkin, I. A., \& Kuzina, E. A. (2020). Actualization of Existing Experience 
Sozinov, A., Bakhchina, A., \& Alexandrov, Y. (2021). The way of learning preserved in the structure of individual experience shapes task-switching: Implications for neuroscience and education, International Journal of Cognitive Research in Science, Engineering and Education (IJCRSEE), 9(2), 291-299.

and Features of Subsequent Learning. Experimental Psychology (Russia), 13(3), 118-131. https://doi.org/10.17759/ expsy.2020130309

Thompson, L. T., \& Best, P. J. (1990). Long-term stability of the place-field activity of single units recorded from the dorsal hippocampus of freely behaving rats. Brain Research, 509(2), 299-308. https://doi.org/10.1016/0006-8993(90)90555-P

Timofeeva, N. O., Ivlieva, N. Y., Semikopnaya, I. I., \& Naryshkin, A. V. (1997). Interactions between homogeneous conditioned motor reflexes during conditioned reflex switching: Transfer of learning and interference. Neuroscience and Behavioral Physiology, 27(1), 30-37. https://doi.org/10.1007/BF02463043

Tonegawa, S., Morrissey, M. D., \& Kitamura, T. (2018). The role of engram cells in the systems consolidation of memory. In Nature Reviews Neuroscience 19(8), 485-498. Nature Publishing Group. https://doi.org/10.1038/s41583-018-0031-2

Umemoto, A., \& Holroyd, C. B. (2016). Exploring individual differences in task switching: Persistence and other personality traits related to anterior cingulate cortex function. In Progress in Brain Research, 229, 189-212. Elsevier B.V. https:// doi.org/10.1016/bs.pbr.2016.06.003

Velichkovsky, B. B., \& Ziberova, A. (2021). Foreign language proficiency, typological similarity to L1, and cognitive control. In B. M. Velichkovsky, P. M. Balaban, \& V. L. Ushakov (Eds.), Advances in Intelligent Systems and Computing, 1358, 335-344. Springer. https://doi.org/10.1007/978-3-030-71637-0_39

Vermeylen, L., Braem, S., \& Notebaert, W. (2019). The affective twitches of task switches: Task switch cues are evaluated as negative. Cognition, 183, 124-130. https://doi.org/10.1016/j.cognition.2018.11.002

Wasylyshyn, C., Verhaeghen, P., \& Sliwinski, M. J. (2011). Aging and Task Switching: A Meta-Analysis. Psychology and Aging, 26(1), 15-20. https://doi.org/10.1037/a0020912

Weible, A. P. (2013). Remembering to attend: The anterior cingulate cortex and remote memory. Behavioural Brain Research, 245, 63-75. https://doi.org/10.1016/j.bbr.2013.02.010

Weible, A. P., Rowland, D. C., Pang, R., \& Kentros, C. (2009). Neural Correlates of Novel Object and Novel Location Recognition Behavior in the Mouse Anterior Cingulate Cortex. Journal of Neurophysiology, 102(4), 2055-2068. https:// doi.org/10.1152/jn.00214.2009

Wylie, G., \& Allport, A. (2000). Task switching and the measurement of "switch costs." Psychological Research, 63(3-4), 212-233. https://doi.org/10.1007/s004269900003

Yeung, N., \& Monsell, S. (2003). Switching Between Tasks of Unequal Familiarity: The Role of Stimulus-Attribute and ResponseSet Selection. Journal of Experimental Psychology: Human Perception and Performance, 29(2), 455-469. https://doi. org/10.1037/0096-1523.29.2.455

Zdanevych, L. V., Buchkivska, G. V., Greskova, V. V., Andriievskyi, B. M., \& Perminova, L. A. (2020). Creativity Formation in the Context of Social and Psychological Adaptation of Preschoolers Aged 5-6 Years. International Journal of Cognitive Research in Science, Engineering and Education, 8(Special issue), 79-91. https://doi.org/10.23947/2334-8496-20208-SI-79-91

Zhang, W. H., \& Williams, Z. M. (2015). Frontal neurons modulate memory retrieval across widely varying temporal scales. Learning and Memory, 22(6), 299-306. https://doi.org/10.1101//m.036806.114

Zhao, X., Wang, H., \& Maes, J. H. R. (2020). Training and transfer effects of extensive task-switching training in students. Psychological Research, 84(2), 389-403. https://doi.org/10.1007/s00426-018-1059-7 
Sozinov, A., Bakhchina, A., \& Alexandrov, Y. (2021). The way of learning preserved in the structure of individual experience shapes task-switching: Implications for neuroscience and education, International Journal of Cognitive Research in Science, Engineering and Education (IJCRSEE), 9(2), 291-299. 